\title{
Desempenho Produtivo de Vacas Leiteiras Alimentadas com Silagem Pré-Seca de Alfafa Adicionada de Inoculante Microbiano ${ }^{1}$
}

\author{
Vanessa Jaime de Almeida Magalhães ${ }^{2}$, Paulo Henrique Mazza Rodrigues ${ }^{3}$
}

\begin{abstract}
RESUMO - Objetivou-se, com o presente estudo, avaliar os efeitos da inoculação microbiana da silagem pré-seca de alfafa sobre o consumo de matéria seca, a produção e composição do leite de vacas da raça Holandesa, multíparas, com 135 \pm 16,4 dias de lactação, distribuídas em delineamento em reversão simples com seqüência balanceada (“cross-over”), com dois períodos sucessivos. Os tratamentos corresponderam à silagem pré-seca de alfafa (50,0\% de MS e 16,5\% de PB) controle ou inoculada com o produto Silobac ${ }^{\circledR}$ (Lactobacillus plantarum e Pediococcus pentosaceus). Cada período experimental teve duração de 21 dias, sendo os cinco últimos dias destinados à coleta de dados. Não se observou efeito da inoculação sobre o CMS (inoculada = 17,8 vs. controle = 17,8 kg/animal $/ \mathrm{dia}$ ), a produção de leite corrigida para 4,0\% de gordura (21,0 vs. 20,4 kg/dia), produção de leite (23,0 vs. 22,4 kg/dia), porcentagem de gordura (3,46 vs. $3,47 \%)$, proteína (2,96 vs. $2,93 \%)$, lactose $(4,64$ vs. 4,67\%), sólidos totais $(11,9$ vs. 11,9\%) e sólidos desengordurados $(8,49$ vs. $8,48 \%)$, CCS (5,43 vs. $5,16 \log$ cel $\left./ 10^{3} / \mathrm{mL}\right)$, NUL (11,7 vs. $\left.12,1 \mathrm{mg} / \mathrm{dl}\right)$, acidez $\left(15,9\right.$ vs. $\left.16,4^{\circ} \mathrm{D}\right)$, densidade $(1030,1 \mathrm{vs.} 1030,0)$ e crioscopia $\left(-0,529\right.$ vs. $\left.-0,531^{\circ} \mathrm{H}\right)$.
\end{abstract}

Palavras-chave: bactérias láticas, produção de leite, Medicago sativa

\section{Performance of Lactating Dairy Cows Fed Alfalfa Haylage with Microbial Inoculant}

\begin{abstract}
The objective of this study was to evaluate the effects of feeding alfalfa haylage with microbial inoculat on dry matter intake, milk yield and composition in Holstein cows, at $135 \pm 16.4$ days in milk. A cross-over design with two periods of sampling was used. Treatments were alfalfa haylage $(50.0 \% \mathrm{DM}$ and $16.5 \% \mathrm{CP})$ control or microbially inoculated with Silobac ${ }^{\circledR}$ product (Lactobacillus plantarum and Pediococcus pentosaceus). Each experimental period extended for twenty-one days, the last five used for data collection. The inoculation did not influence DMI (inoculated $=17.8 \mathrm{vs}$. control $=17.8 \mathrm{~kg} / \mathrm{animal} / \mathrm{day}$ ), $4 \% \mathrm{FCM}$ ( 21.0 vs. $20.4 \mathrm{~kg} /$ day), milk yield (23.0 vs. $22.4 \mathrm{~kg} / \mathrm{day})$, fat (3.46 vs. $3.47 \%)$, protein (2.96 vs. $2.93 \%)$, lactose (4.64 vs. $4.67 \%)$, total solids (11.9 vs. $11.9 \%)$ and fat free solids percentage ( 8.49 vs. $8.48 \%)$, SCC (5.43 vs. $5.16 \log$ cell/10 $3 / \mathrm{mL})$, MUN (11.7 vs. $12.1 \mathrm{mg} / \mathrm{dl})$, acidity $\left(15.9\right.$ vs. $\left.16.4^{\circ} \mathrm{D}\right)$, density (1030.1 vs. 1030.0$)$ and cryoscopic index $\left(-0.529\right.$ vs. $\left.-0.531^{\circ} \mathrm{H}\right)$.
\end{abstract}

Key Words: lactic acid bacteria, milk yield, Medicago sativa

\section{Introdução}

Para produzir uma silagem de qualidade, é necessário manter o meio anaeróbio, com substrato adequado para as bactérias produtoras de ácido lático e uma população dessas bactérias em quantidade suficiente para que a fermentação ocorra (Muck, 1988).

Assim, para se dominar a fase inicial do processo fermentativo da silagem, tem sido observado o uso de inoculantes contendo bactérias ácido láticas (Bolsen et al., 1989). As mudanças esperadas com a inoculação incluem rápido declínio no $\mathrm{pH}$, diminuição na concentração de nitrogênio amoniacal, decréscimo nos níveis de acetato e butirato e aumento no conteúdo de ácido lático (Kung Jr. et al., 1984).
Contudo, os efeitos da inoculação microbiana na silagem de alfafa são bastante variáveis (Muck, 1988). Melhoria das características fermentativas da silagem (Gordon, 1989; Freeden et al., 1991) e diminuição das perdas de matéria seca (Rice et al., 1990), observadas com a inoculação, nem sempre resultam em melhoria do valor nutricional, consumo voluntário ou desempenho animal (Stokes, 1992).

Entretanto, alguns estudos demonstraram que o uso de aditivos na ensilagem promove melhoria no consumo do alimento, na produção de leite (Mayne \& Steen, 1993), na fermentação da silagem, na digestibilidade da dieta e no desempenho animal (Henderson et al., 1987; Appleton \& Done, 1987; Rooke et al., 1988; Anderson et al., 1989).

\footnotetext{
1 Projeto financiado pela Fundação de Amparo à Pesquisa do Estado de São Paulo (FAPESP).

2 Aluna de Pós-graduação do Departamento de Nutrição e Produção Animal -FMVZ/USP. Bolsista FAPESP. vjdamagalhaes@hotmail.com

${ }^{3}$ Professor do Departamento de Nutrição e Produção Animal - FMVZ/USP, Av. Duque de Caxias Norte, 225 - CEP. 13630-000, Pirassununga-SP. E.mail: pmazza@usp.br
} 
Objetivou-se, com o presente estudo, avaliar os efeitos da inoculação microbiana da silagem pré-seca de alfafa sobre o consumo de matéria seca, a produção e a composição do leite de vacas leiteiras multíparas.

\section{Material e Métodos}

O trabalho foi conduzido nas dependências do Departamento de Nutrição e Produção Animal da Faculdade de Medicina Veterinária e Zootecnia da Universidade de São Paulo (Campus de Pirassununga).

A cultura de alfafa foi cortada em dezembro de 2000, quando em estádio do meio do florescimento. Após colhido e pré-seco por 4 horas, o material original foi acondicionado em fardos com aproximadamente $150 \mathrm{~cm}$ de altura e $150 \mathrm{~cm}$ de diâmetro (capacidade de 600 quilos), revestidos com película de PVC branca. Os silos foram divididos em dois tratamentos, um controle e outro com adição do inoculante comercial Silobac ${ }^{\circledR}$, segundo as recomendações do fabricante. De acordo com essas recomendações, o produto fornece $1,0 \times 10^{5}$ unidades formadoras de colônia (Lactobacillus plantarum e Pediococcus pentosaceus) por grama de forragem. O inoculante comercial Silobac ${ }^{\circledR}$ foi escolhido em função de melhores resultados obtidos, ao se avaliarem os inoculantes Sil-All ${ }^{\circledR}$, Pioneer $1174^{\circledR} \mathrm{e}$ Silobac ${ }^{\circledR}$, em ensaios fermentativos com cultura de alfafa ensilada em silos experimentais (resultados não publicados). A alfafa foi escolhida por ser a cultura que apresentou as maiores respostas à inoculação, quando comparada às silagens de milho, sorgo, girassol ou capim-elefante.

Aproximadamente $600 \mathrm{~kg}$ de massa úmida foram colocadas em cada silo, correspondendo a uma compactação de aproximadamente $230 \mathrm{~kg}$ de silagem $/ \mathrm{m}^{3}$. Os silos foram mantidos fechados por 60 dias, expostos às intempéries.

Foram utilizadas 12 vacas Holandesas, com $135 \pm$ 16,4 dias de lactação, alojadas em baias individuais, presas por corrente (sistema tie-stall). O delineamento experimental foi de reversão simples com seqüência balanceada (cross-over), com dois períodos de coletas, adicionados das covariáveis produção de leite e dias em lactação, observados ao início do experimento, e os tratamentos compostos pelas silagens controle ou inoculada, na proporção de $50 \%$ concentrados e $50 \%$ de volumosos na dieta (Tabelas 1 e 2). A ração foi fornecida em duas refeições, às 8 e $16 \mathrm{~h}$, sendo a silagem oferecida juntamente com o concentrado, permitindo-se $15 \%$ de sobras.

Constam na Tabela 2 as rações utilizadas e os resultados das análises bromatológicas.

O período experimental teve duração total de 42 dias, sendo 21 dias para cada período, dos quais os primeiros 16 dias foram destinados à adaptação dos animais às dietas; nos últimos cinco dias, foram realizadas mensurações do consumo e nos três últimos, coleta de leite das duas ordenhas. Para compor uma amostra final, o leite foi amostrado duas vezes ao dia, durante as ordenhas.

As análises dos componentes do leite (gordura, proteína, lactose e sólidos totais) foram realizadas por infravermelho, por meio do equipamento Bentley $2000^{\circledR}$ (Bentley Instruments, Chaska, MN). A determinação da densidade do leite foi realizada por termolactodensímetro; a acidez, pelo método de Dornic; e o índice crioscópico, com a utilização do aparelho Crioscópio Eletrônico Digital ITR-MK540, segundo MINISTÉRIO DA AGRICULTURA (1981). A determinação da contagem de células somáticas no leite (CCS) foi realizada por citometria de fluxo, utilizando o aparelho Somacount $300^{\circledR}$ (Bentley Instruments, Chaska, MN). A determinação dos níveis de nitrogênio uréico no leite (NUL) foi realizada

Tabela 1 - Composição bromatológica da silagem pré-seca de alfafa controle e inoculada (porcentagem com base na MS)

Tabela 1 - Chemical composition of control and inoculated alfalfa haylages (DM basis)

\begin{tabular}{lcccccccccc}
\hline Silagem & MS & PB & EE & MM & FB & FDN & FDA & Amido & Ca & P \\
Silage & $D M$ & $C P$ & $E E$ & $A s h$ & $C F$ & $N D F$ & $A D F$ & Starch & $C a$ & $P$ \\
\hline $\begin{array}{l}\text { Controle } \\
\begin{array}{l}\text { Control } \\
\text { Inoculada }\end{array}\end{array}$ & 51,96 & 16,58 & 1,76 & 11,44 & 30,82 & 47,72 & 40,34 & 1,36 & 0,83 & 0,31 \\
\begin{tabular}{l} 
Inoculated \\
\hline
\end{tabular} & & 16,32 & 2,00 & 11,85 & 31,34 & 46,10 & 40,93 & 0,92 & 0,79 & 0,33 \\
\hline
\end{tabular}

R. Bras. Zootec., v.32, n.6, p.2016-2022, 2003 (Supl. 2) 
por colorimetria enzimática, por meio do equipamento ChemSpeck $150^{\circledR}$ (Bentley Instruments, Chaska, MN).

As análises bromatológicas de matéria seca (MS), proteína bruta $(\mathrm{PB})$, extrato etéreo (EE), fibra bruta (FB), matéria mineral (MM), amido, cálcio $(\mathrm{Ca})$ e fósforo $(\mathrm{P})$ dos ingredientes da dieta foram realizadas segundo AOAC (1980) e de fibra em detergente neutro (FDN) e fibra em detergente ácido (FDA) segundo Goering \& Van Soest (1979). Para a análise de FDN, foi omitido o sulfito de sódio, mas adicionada a $\alpha$-amilase.

Os resultados foram analisados utilizando-se o software computacional Statistical Analysis System (SAS, 1998). Os dados foram submetidos à análise de variância pelo procedimento GLM (PROC GLM), que separaram como causas de variação o efeito de tratamento, efeito de período e as covariáveis produção de leite e dias em lactação, ao início do experimento. Foi utilizado o nível de significância de 5\%.

\section{Resultados e Discussão}

Os dados de consumo dos animais submetidos à silagem controle e inoculada encontram-se na Tabela 3.

A adição de inoculante à silagem pré-seca de alfafa não aumentou o consumo de matéria seca (CMS), fossem os dados expressos em quilos/animal/ dia, em porcentagem do peso vivo ou porcentagem do peso metabólico. De forma geral, o CMS, que, em média, foi de 3,3\% do peso vivo, apresentou-se dentro do esperado, uma vez que a fermentação das silagens controle ou inoculada apresentou-se aparentemente normal, sem fermentações indesejáveis.

Semelhantemente ao observado nesta pesquisa, Grieve et al. (1982), Kung Jr. et al. (1984), Mader et al. (1985), Kent et al. (1988) e Phillip et al. (1990) não observaram resultados positivos da inoculação sobre o consumo de silagem de alfafa, enquanto Kent et al. (1988) descreveram tendência de aumento do consumo $(\mathrm{P}<0,10)$ por vacas em lactação alimentadas com silagem de alfafa inoculada com $L$. plantarum e $P$. acidilactici, mas este efeito não foi estatisticamente significativo.

Já McAllister et al. (1998) observaram efeitos dos inoculantes microbianos em aumentar o CMS da silagem de alfafa por ovinos. Este mesmo comportamento foi descrito por Patterson et al. (1996), quando utilizaram inoculante microbiano em silagem de gramínea, e Patterson et al. (1997), ao adicionarem ácido fórmico em silagem de gramínea para bovinos.
Os resultados da produção e composição do leite, em resposta à inoculação microbiana da silagem préseca de alfafa, encontram-se na Tabela 4.

A inoculação da silagem pré-seca de alfafa não aumentou a produção de leite, do leite corrigido para

Tabela 2 - Proporções de ingredientes utilizados e composição bromatológica das rações, com base na matéria seca

Tabela 2 - Ingredients and chemical composition of diets, with DM basis

\begin{tabular}{|c|c|c|}
\hline \multirow{3}{*}{$\begin{array}{l}\text { Ingredientes (\%) } \\
\text { Ingredients }(\%)\end{array}$} & \multicolumn{2}{|c|}{$\begin{array}{c}\text { Tratamentos } \\
\text { Treatments }\end{array}$} \\
\hline & Controle & Inoculada \\
\hline & Control & Inoculated \\
\hline Silagem de alfafa & 50,0 & - \\
\hline \multicolumn{3}{|l|}{ Alfalfa haylage } \\
\hline Silagem de alfafa inoculada & - & 50,0 \\
\hline \multicolumn{3}{|l|}{ Inoculated alfalfa haylage } \\
\hline Grãos de milho moído & 40,5 & 40,5 \\
\hline \multicolumn{3}{|l|}{ Corn grain, ground } \\
\hline Grãos de soja extrusados & 7,5 & 7,5 \\
\hline \multicolumn{3}{|l|}{ Whole soy bean, extrused } \\
\hline Calcário calcítico & 0,10 & 0,10 \\
\hline \multicolumn{3}{|l|}{ Limestone } \\
\hline Sal branco & 0,63 & 0,63 \\
\hline \multicolumn{3}{|l|}{ White salt } \\
\hline Mistura mineral $^{1}$ & 1,21 & 1,21 \\
\hline \multicolumn{3}{|l|}{ Mineral mixture } \\
\hline \multicolumn{3}{|l|}{ Composição } \\
\hline $\mathrm{MS}(\%)$ & 65,4 & 61,7 \\
\hline \multicolumn{3}{|l|}{$D M(\%)$} \\
\hline $\mathrm{PB}(\%)$ & 15,8 & 15,7 \\
\hline \multicolumn{3}{|l|}{$C P(\%)$} \\
\hline Proteína degradável (\%) & 10,7 & 10,6 \\
\hline \multicolumn{3}{|l|}{ Rumen degrad. protein (\%) } \\
\hline Proteína não degradável (\%) & 5,1 & 5,1 \\
\hline \multicolumn{3}{|l|}{ Undegradable protein (\%) } \\
\hline $\operatorname{FDA}(\%)$ & 22,3 & 22,6 \\
\hline \multicolumn{3}{|l|}{$A D F(\%)$} \\
\hline FDN $(\%)$ & 28,8 & 28,0 \\
\hline \multicolumn{3}{|l|}{$N D F(\%)$} \\
\hline $\mathrm{EE}(\%)$ & 2,7 & 2,8 \\
\hline \multicolumn{3}{|l|}{$E E(\%)$} \\
\hline Energia líq. lact. (Mcal/kg) & 1,53 & 1,53 \\
\hline \multicolumn{3}{|l|}{$N E_{L}(\mathrm{Mcal} / \mathrm{kg})$} \\
\hline $\mathrm{Ca}(\%)$ & 0,70 & 0,70 \\
\hline \multicolumn{3}{|l|}{$\mathrm{Ca}(\%)$} \\
\hline $\mathrm{P}(\%)$ & 0,40 & 0,50 \\
\hline$P(\%)$ & & \\
\hline \multicolumn{3}{|c|}{$\begin{array}{l}{ }^{1} \text { Composição por kg de mistura mineral: } 180 \mathrm{~g} \mathrm{Ca}, 90 \mathrm{~g} \mathrm{P}, 20 \mathrm{~g} \\
\mathrm{Mg}, 20 \mathrm{~g} \mathrm{~S}, 100 \mathrm{~g} \mathrm{Na}, 3.000 \mathrm{mg} \mathrm{Zn}, 1.000 \mathrm{mg} \mathrm{Cu}, 1.250 \mathrm{mg} \mathrm{Mn} \text {, } \\
2.000 \mathrm{mg} \mathrm{Fe}, 200 \mathrm{mg} \text { Co, } 90 \mathrm{mg} \mathrm{I}, 36 \mathrm{mg} \mathrm{Se}, 900 \mathrm{mg} \mathrm{F} \text { (máximo). } \\
{ }^{1} \text { Composition per kg of mineral mixture: } 180 \mathrm{~g} \mathrm{Ca}, 90 \mathrm{~g} \mathrm{P}, 20 \mathrm{~g} \mathrm{Mg} \text {, } \\
20 \mathrm{~g} \mathrm{~S}, 100 \mathrm{~g} \mathrm{Na}, 3.000 \mathrm{mg} \mathrm{Zn,} 1.000 \mathrm{mg} \mathrm{Cu}, 1.250 \mathrm{mg} \mathrm{Mn}, 2.000 \mathrm{mg} \\
\mathrm{Fe}, 200 \mathrm{mg} \mathrm{Co}, 90 \mathrm{mg} \mathrm{l}, 36 \mathrm{mg} \mathrm{Se}, 900 \mathrm{mg} \text { F (maximum). }\end{array}$} \\
\hline
\end{tabular}


Tabela 3 - Consumo de matéria seca obtido com silagens pré-secadas de alfafa submetidas ou não à aplicação de inoculante ${ }^{1}$

Table 3 - Dry matter intake obtained with control or inoculated alfalfa haylages

\begin{tabular}{|c|c|c|c|c|c|}
\hline & \multicolumn{2}{|c|}{$\begin{array}{c}\text { Tratamentos } \\
\text { Treatments }\end{array}$} & \multirow[b]{2}{*}{$\begin{array}{l}\text { Média } \\
\text { Mean }\end{array}$} & \multirow[b]{2}{*}{$\begin{array}{l}\mathrm{CV} \\
\mathrm{CV}\end{array}$} & \multirow[b]{2}{*}{$\begin{array}{l}\text { Prob. } \\
\text { Prob. }\end{array}$} \\
\hline & $\begin{array}{c}\text { Controle } \\
\text { Control }\end{array}$ & $\begin{array}{l}\text { Inoculada } \\
\text { Inoculated }\end{array}$ & & & \\
\hline $\begin{array}{l}\mathrm{CMS} \\
D M I\end{array}$ & 17,82 & 17,84 & 17,83 & 13,46 & NS \\
\hline $\begin{array}{l}\text { CMSPV } \\
B W D M I\end{array}$ & 3,30 & 3,28 & 3,29 & 14,40 & NS \\
\hline $\begin{array}{l}\text { CMSPV }^{0,75} \\
B W^{0,75} D M I\end{array}$ & 159,08 & 158,47 & 158,47 & 13,75 & NS \\
\hline
\end{tabular}

CMS: consumo de matéria seca (kg/animal/dia), CMSPV: consumo de matéria seca em função do peso vivo (\%), CMSPV 0,75 : consumo de matéria seca em gramas por $\mathrm{kg}$ de peso vivo metabólico ( $\mathrm{g} / \mathrm{kg}$ de $\mathrm{PV} 0,75)$, CV: coeficiente de variação (\%), Prob: probabilidades estatísticas, NS: não significativo.

DMI: dry matter intake (g/animal/day), BWDMI: body weight dry matter intake (\%), BW ${ }^{0,75} \mathrm{DMI}$ : grams of dry matter intake per $\mathrm{kg}$ of metabolic body weight (g/kg of BW0,75), CV: coefficient of variation (\%); Prob: statistical probability; NS: not significant.
4,0\% de gordura, a produção e composição de gordura, proteína, lactose, sólidos totais e sólidos desengordurados, o que está de acordo com os estudos realizados por Chamberlain et al. (1987), que não observaram efeito algum da inoculação, Fredeen et al. (1991) e Mayne (1993), quando avaliaram a inoculação de silagens de gramíneas. Tais resultados concordam também com os relatos de Kent et al. (1989), que, utilizando silagem de alfafa pré-seca e inoculada, não notaram efeito sobre a produção de leite, LCG 3,5\% e produção e composição de gordura, proteína e lactose, e os estudos de Patterson et al. (1997) e Gasior \& Brzoska (2000), que também não observaram aumento na produção e composição do leite de vacas, quando utilizaram silagens de gramíneas com ácido fórmico ou inoculante microbiano.

Por outro lado, Martinsson (1991) demonstrou aumento significativo na produção de leite de vacas

Tabela 4 - Efeitos da inoculação microbiana sobre a produção e composição do leite ${ }^{1}$ Table 4 - Effects of microbial inoculation on milk production and composition

\begin{tabular}{|c|c|c|c|c|c|}
\hline & \multicolumn{2}{|c|}{$\begin{array}{c}\text { Tratamentos } \\
\text { Treatments }\end{array}$} & \multirow[b]{2}{*}{$\begin{array}{l}\text { Média } \\
\text { Mean }\end{array}$} & \multirow[b]{2}{*}{$\begin{array}{l}\mathrm{CV} \\
\mathrm{CV}\end{array}$} & \multirow[b]{2}{*}{$\begin{array}{l}\text { Prob } \\
\text { Prob }\end{array}$} \\
\hline & $\begin{array}{l}\text { Controle } \\
\text { Control }\end{array}$ & $\begin{array}{l}\text { Inoculada } \\
\text { Inoculated }\end{array}$ & & & \\
\hline $\begin{array}{l}\text { Produção de leite } \\
\text { Milk yield }\end{array}$ & 22,37 & 22,98 & 22,69 & 11,97 & NS \\
\hline $\begin{array}{l}\text { LCG } 4,0 \% \\
4.0 \% F C M\end{array}$ & 20,41 & 21,00 & 20,69 & 13,99 & NS \\
\hline $\begin{array}{l}\text { Gordura } \\
\text { Fat }\end{array}$ & 3,47 & 3,46 & 3,46 & 10,40 & NS \\
\hline $\begin{array}{l}\text { Produção de gordura } \\
\text { Fat yield }\end{array}$ & 0,769 & 0,781 & 0,774 & 12,28 & NS \\
\hline $\begin{array}{l}\text { Proteína } \\
\text { Protein }\end{array}$ & 2,93 & 2,96 & 2,95 & 11,15 & NS \\
\hline $\begin{array}{l}\text { Produção de proteína } \\
\text { Protein yield }\end{array}$ & 0,649 & 0,674 & 0,661 & 14,60 & NS \\
\hline $\begin{array}{l}\text { Lactose } \\
\text { Lactose }\end{array}$ & 4,67 & 4,64 & 4,66 & 5,54 & NS \\
\hline $\begin{array}{l}\text { Produção de lactose } \\
\text { Lactose yield }\end{array}$ & 1,049 & 1,073 & 1,062 & 21,64 & NS \\
\hline $\begin{array}{l}\text { Sólidos totais } \\
\text { Total solids }\end{array}$ & 11,94 & 11,88 & 11,91 & 5,22 & NS \\
\hline $\begin{array}{l}\text { Prod. sólidos totais } \\
\text { Total solids yield }\end{array}$ & 2,65 & 2,74 & 2,69 & 15,84 & NS \\
\hline $\begin{array}{l}\text { Sólidos desengor. } \\
\text { Fat free solids }\end{array}$ & 8,48 & 8,49 & 8,49 & 3,85 & NS \\
\hline $\begin{array}{l}\text { Prod. sólidos desengor. } \\
\text { Fat free solids yield }\end{array}$ & 1,89 & 1,95 & 1,92 & 17,86 & NS \\
\hline
\end{tabular}

Produção de leite (kg/dia), LCG 4,0\%: produção de leite corrida para 4\% de gordura (kg/dia), Gordura (\%), Produção de gordura (kg/dia), Proteína (\%), Produção de proteína (kg/dia), Lactose (\%), Produção de lactose $(\mathrm{kg} / \mathrm{dia})$, Sólidos totais (\%), Prod. sólidos totais: produção de sólidos totais (kg/dia), Sólidos desengor.: sólidos desengordurados (\%), Prod. sólidos desengor.: produção de sólidos desengordurados (kg/dia), CV: coeficiente de variação (\%), Prob: probabilidades estatísticas, NS: não significativo. Milkyield (kg/day), 4.0\% FCM (kg/day), Fat (\%), Fat yield (kg/day), Protein (\%), Protein yield (kg/day), Lactose (\%), Lactose yield (kg/day), Total solids (\%), Total solids yield (kg/day), Fat free solids (\%), Fat free solids yield (kg/day), CV: coefficient of variation (\%); Prob: statistical probability; NS: not significant. 
tratadas com silagem de gramínea pré-seca e inoculada, Chamberlain et al. (1992) observaram aumento significativo na produção e composição da gordura no leite, Mayne (1990) notou aumento na proteína do leite, mas não na gordura, e Kung Jr. et al. (1987) observaram aumento na produção de leite no primeiro ano, mas não no ano seguinte, com a inoculação da silagem de alfafa. A revisão de Moran \& Owen (1994) revelou, ainda, que a inoculação das silagens de alfafa, milho ou gramínea aumentou a produção de leite.

Entretanto, Chen et al. (1994), utilizando silagem de gramíneas e trevo, inoculada com enzimas, verificaram diminuição na produção de leite, de proteína e de sólidos desengordurados, mas não observaram efeito sobre a produção de leite corrigida para 3,5\% de gordura, bem como para produção e composição de gordura e composição de proteína, enquanto Patterson et al. (1996) observaram que a inoculação da silagem de gramínea aumentou a produção de gordura, porém reduziu a mesma com a utilização da silagem pré-seca. Já para a composição de gordura, proteína e lactose do leite, nenhum efeito foi demonstrado.

Alguns estudos apresentaram efeito na produção de leite com a inoculação de várias forrageiras na ensilagem, incluindo a alfafa (Colenbrander et al. 1988) e o milho (Wohlt, 1989).

A proteína da alfafa está sujeita a sofrer extensa degradação, durante o processo de ensilagem, po- dendo estar, na forma de nitrogênio não protéico (NNP), aproximadamente de 75 a $87 \%$ do total de nitrogênio presente na silagem (Muck, 1987). Estudos revelaram que o excesso de degradação ruminal resulta em um ineficiente aproveitamento da proteína da alfafa, o que pode diminuir o rendimento leiteiro e a própria proteína do leite (Broderick, 1985).

Segundo Muck \& Kung Jr. (1997), as bactérias ácido láticas (ácido-tolerantes) epfíticas são as que mais competem com o inoculante, mas, se a adição deste último corresponder a pelo menos um décimo da população dessas bactérias, será capaz de sobrepôlas e melhorar a fermentação. Entretanto, para melhorar o desempenho animal, como por exemplo a produção de leite, Satter et al. (1991) verificaram, com a inoculação da silagem de alfafa, ser necessário que a adição de inoculante seja, pelo menos, 10 vezes maior que a população de bactérias ácido-tolerantes da forragem inicial.

É possível que a qualidade da silagem controle obtida no presente experimento já estivesse boa o suficiente para permitir melhoras com a inoculação. Embora não se disponha da contagem de bactérias epfíticas inicial, no presente experimento, também é possível que a adição de bactérias ácido láticas não tenha sido grande o suficiente para permitir melhoras na qualidade da silagem.

Os resultados das características físico-químicas do leite, em resposta à inoculação microbiana da

Tabela 5 - Efeitos da inoculação microbiana sobre a CCS, NUL e características físicoquímicas do leite 1

Table 5 - Effects of microbial inoculation on SCC, MUN and physic-chemical characteristics of milk

\begin{tabular}{|c|c|c|c|c|c|}
\hline & \multicolumn{2}{|c|}{$\begin{array}{c}\text { Tratamentos } \\
\text { Treatments }\end{array}$} & \multirow[b]{2}{*}{$\begin{array}{c}\text { Média } \\
\text { Mean }\end{array}$} & \multirow[b]{2}{*}{$\begin{array}{l}\mathrm{CV} \\
\mathrm{CV}\end{array}$} & \multirow[b]{2}{*}{$\begin{array}{l}\text { Prob. } \\
\text { Prob. }\end{array}$} \\
\hline & $\begin{array}{c}\text { Controle } \\
\text { Control } \\
\end{array}$ & $\begin{array}{c}\text { Inoculada } \\
\text { Inoculated }\end{array}$ & & & \\
\hline$\overline{\mathrm{CCS}}$ & & & & & \\
\hline $\begin{array}{l}S C C \\
\text { NUL }\end{array}$ & 5,16 & 5,43 & 5,29 & 30,41 & NS \\
\hline $\begin{array}{l}\text { MUN } \\
\text { Acidez }\end{array}$ & 12,07 & 11,65 & 11,87 & 16,87 & NS \\
\hline $\begin{array}{l}\text { Acidity } \\
\text { Densidade }\end{array}$ & 16,35 & 15,89 & 16,14 & 8,40 & NS \\
\hline $\begin{array}{l}\text { Density } \\
\text { Crioscopia }\end{array}$ & 1030,04 & 1030,08 & 1030,06 & 0,12 & NS \\
\hline Cryoscopic index & $-0,531$ & $-0,529$ & $-0,530$ & $-0,748$ & NS \\
\hline
\end{tabular}


silagem pré-seca de alfafa, encontram-se na Tabela 5.

No presente estudo, observou-se também ausência de efeitos da inoculação sobre a CCS, o NUL, a acidez, a densidade e a crioscopia do leite, embora dados semelhantes obtidos com a inoculação não estejam disponíveis na literatura.

\section{Conclusões}

O uso do inoculante microbiano Silobac ${ }^{\circledR}$ na silagem pré-seca de alfafa não apresentou efeito significativo $(\mathrm{P}<0,05)$ para produção, composição e qualidade do leite.

\section{Agradecimento}

Aos funcionários Everson Lázaro e Gilmar Botteon, pelo cuidado com os animais, e aos técnicos Ari de Castro, Gilson de Godoy, Lucinéia Mestieri e Simi Robassini, pela ajuda com as análises laboratoriais.

\section{Literatura Citada}

ANDERSON, R.; GRACEY, H.I.; KENNEDY, S.J. et al. Evaluation studies in the development of a commercial bacterial inoculant as an additive for grass silage. 1. Using pilot scale tower silos. Grass Forage Science, v.44, n.4, p.361-369, 1989.

APPLETON, M.; DONE, D. The effect of an inoculant silage additive on the fermentation of grass and animal performance. In: SILAGE CONFERENCE, 8., 1987, Hurley. Proceedings ... Hurley: Institute for Grassland and Animal Production. 1987. p.15-16.

ASSOCIATION OF OFFICIAL ANALYTICAL CHEMISTS AOAC. Official methods of analysis. 10. ed. Washington, D.C.: Association of Analytical Chemistry. 1980. 1015p.

BOLSEN, K.K.; LAYTINI, A.; HART, R.A. et al. Effect of commercial inoculants on fermentation of 1987 and 1988. Kansas Silage Crops. Des Moines: Pionner Hi-Bred Int., 1989. p. 1-19.

BRASIL. Ministério da Agricultura. Secretaria Nacional de Defesa Agropecuária. Laboratório Nacional de Referência Animal - LANARA. Métodos analíticos oficiais para controle de produtos de origem animal e seus ingredientes: métodos físicos e químicos. Brasília: LANARA, 1981. v.2.

BRODERICK, G.A. Alfalfa silage or hay versus corn silage as the sole forage for lactating dairy cows. Journal of Dairy Science, v.68, n.12, p.3262-3271, 1985.

CHAMBERLAIN, D.G.; MARTIN, P.A.; ROBERTSON, S. et al. Effects of the type of additive and the type of supplement on the utilization of grass silage for milk production in dairy cows. Grass Forage Science, v.47, n.4, p.391-399, 1992.

CHAMBERLAIN, D.G.; THOMAS, P.C.; ROBERTSON, S. The effect of formic acid, bacterial inoculants and enzyme additives on feed intake and milk production in cows given silage of high or moderate digestibility with two levels of supplementary concentrates. In: SILAGE CONFERENCE, 8., 1987, Hurley. Proceedings... Hurley: Institute for
Grassland and Animal Production. 1987, p.31-32.

CHEN, J.; STOKES, M.R.; WALLACE, C.R. Effects of enzymeinoculant systems on preservation and nutritive value of haycrop and corn silages. Journal of Dairy Science, v.77, n.2, p.501-512, 1994.

COLENBRANDER, V.F.; GRANT, R.J.; SCHAAF, G. Milk production and feed intake of dairy cows fed Lactobacillus inoculated alfalfa silage. Applied Agricultural Research, v.3, n.1, p. 55-59, 1988.

FREDEEN, A.H.; McQUEEN, R.E.; BROWNING, D.A. Effects of enzymes and nutrients in a bacterial inoculant on quality of timothy or alfalfa silage and dairy cow performance. Canadian Journal of Animal Science, v.71, n.3, p.781791, 1991.

GASIOR, R.; BRZOSKA, F. The effects of wilting and additives on silage quality, protein degradation in the silo and in the rumen, and dairy cattle productivity. Annals of Animal Science. Roczniki Naukowe Zootechniki, v.27, n.4, p.129$141,2000$.

GOERING, H.K.; Van SOEST, P.J. Forage fiber analysis: apparatus, reagents, procedures and some applications. Washington. DC.: ARS-USDA, 1979. (Agric. Handbook, n.379).

GORDON, F.J. An evaluation through lactating cattle of a bacterial inoculant as an additive for grass silage. Grass Forage Science, v.44, n.2, p.169-179, 1989.

GRIEVE, D.B.; AHRENS, K.R.; THOMAS, J. W. et al. Production of lactating cows and growing steers fed alfalfa haylage treated with ammonia or a microbial inoculant. Journal of Dairy Science, v.65, p.143, 1982. (Supplement 1)

HENDERSON, A.R.; ANDERSON, D.H.; NEILSON, D.R. et al. The effect of a commercial inoculant and Add-F applied at two levels on the chemical characteristics and utilization of ryegrass silage over two seasons. In: SILAGE CONFERENCE, 8., 1987, Hurley. Proceedings... Hurley: Institute for Grassland and Animal Production. 1987. p.13-14.

KENT, B.A.; ARAMBEL, M.J.; WALTERS, J.L. Effect of bacterial inoculant on alfalfa haylage: ensiling characteristics and milk production response when fed to dairy cows in early lactation. Journal of Dairy Science, v.71, n.9, p.24572461, 1988.

KENT, B.A.; ARAMBEL, M.J.; WINSRYG, M.D. et al. Microbial inoculation of alfalfa haylage: Ensiling characteristics and milk production response when fed to early lactation dairy cows. Journal of Dairy Science, v.72, n.9, p.2325-2330, 1989.

KUNG JR., L.; GRIEVE, D.B.; THOMAS, J.W. et al. Added ammonia or microbial inocula for fermentation and nitrogenous compounds of alfalfa ensiled at various percents of dry matter. Journal of Dairy Science, v.67, n.2, p.299-306, 1984.

KUNG JR., L.; SATTER, L.D.; JONES, B.A. et al. Microbial inoculation of low moisture alfalfa silage. Journal of Dairy Science, v.70, n.10, p.2069-2077, 1987.

MADER, T.L.; BRITTON, R.A.; KRAUSE, V.E. et al. Effect of additive on alfalfa silage fermentation characteristics and feedlot performance of steers. Journal of Dairy Science, v.68, n.7, p.1744-1747, 1985.

MARTINSSON, K. A comparison between formic acid and an inoculant for the preservation of grass silage for dairy cows. Swedish Journal of Agricultural Research, v.21, n.3, p.121-130, 1991.

MAYNE, C.S. An evaluation of an inoculant of Lactobacillus

R. Bras. Zootec., v.32, n.6, p.2016-2022, 2003 (Supl. 2) 
plantarum as an additive for grass silage for dairy cattle. Animal Production, v.51, n.1, p.1-13, 1990.

MAYNE, C.S. The effect of formic acid, sulphuric acid and a bacterial inoculant on silage fermentation and the food intake and milk production of lactating dairy cows. Animal Production, v.56, n.1, p.29-42, 1993.

MAYNE, C.S.; STEEN, R.W.J. A review of animal production responses to formic acid and inoculant treatment of grass silage in trials at the Agricultural Research Institute of Northern Ireland. In: INTERNATIONAL CONFERENCE ON SILAGE RESEARCH, 10., 1993, Dublin. Proceedings... Dublin: Silage Research, 1993. p.178-179.

McALLISTER, T.A.; FENIUK, R.; MIR, Z. et al. Inoculants for alfalfa silage: effects on aerobic stability, digestibility and the growth performance of feedlot steers. Livestock Production Science, v.53, n.2, p.171-181, 1998.

MORAN, J.P.; OWEN, T.R. The effects of Ecosyl treated silage on milk production by lactating cows. In: NATIONAL CONFERENCE ON FORAGE QUALITY, EVALUATION AND UTILIZATION, 1994, Lincoln. Proceedings... Lincoln: University of Nebraska, 1994. p.126.

MUCK, R.E. Dry matter level effects on alfalfa silage quality. I. Nitrogen transformations. Transactions of American Society of Agricultural Engineers, v.30, n.1, p.7-14, 1987.

MUCK, R.E. Factors influencing silage quality and their implications for management. Journal of Dairy Science, v.71, n.11, p.2992-3002, 1988.

MUCK, R.E.; KUNG JR., L. Effects of silage additives on ensiling. In: SILAGE: FIELD TO FEEDBUNK NORTH AMERICA CONFERENCE, 1997, Hershey. Proceedings... Hershey: NRAES, 1997. p.187-199.

PATTERSON, D.C.; MAYNE, C.S.; GORDON, F.J. et al. An evaluation of an inoculant/enzyme preparation as an additive for grass silage for dairy cattle. Grass Forage Science, v.52, n.3, p.325-335, 1997.

PATTERSON, D.C.; YAN, T.; GORDON, F.J. The effects of wilting of grass prior to ensiling on the response to bacterial inoculation. 2. Intake and performance by dairy cattle over three harvests. Animal Science, v.62, n.3, p.419-429, 1996.
PHILLIP, L.E.; UNDERHILL, L.; GARINO, H. Effects of treating lucerne with an inoculum of lactic acid bacteria or formic acid upon chemical changes during fermentation, and upon the nutritive value of the silage for lambs. Grass Forage Science, v.45, n.3, p.337-344, 1990.

RICE, D.W.; SODERLUND, S.D.; PHILLIP, I.E. et al. Effect of microbial inoculation on the digestibility of legume silages. Journal of Dairy Science, v.73, p.195, 1990 (Supplement 1).

ROOKE, J.A.; MAYA, F.M.; ARNOLD, J.A. et al. The chemical composition and nutritive value of grass silages prepared with no additive or with the application of additives containing either Lactobacillus plantarum or formic acid. Grass Forage Science, v.43, n.1, p.87-95, 1988.

STATISTICAL SYSTEM ANALYSES - SAS. SAS user's guide: statistics. 7.ed. Cary: 1998

SATTER, L.D.; MUCK, R.E.; JONES, B.A. et al. Efficacy of bacterial inoculants for lucerne silage. In: FORAGE CONSERVATION TOWARDS 2000, 123., 1991, Braunschweig. Proceedings... Braunschweig:Landbauforschung Voelkenrode. Sonderheft, 1991.p.342-343.

STOKES, M.R. Effects of an enzyme mixture, an inoculant, and their interaction on silage fermentation and dairy production. Journal of Dairy Science, v.75, n.3, p.764-773, 1992.

WOHLT, J.E. Use of a silage inoculant to improve feeding stability and intake of a corn silage-grain diet. Journal of Dairy Science, v.72, n.2, p.545-551, 1989. 